The Journal of Laryngology \& Otology

http://journals.cambridge.org/JLO

Additional services for The Journal of Laryngology \& Otology:

Email alerts: $\underline{\text { Click here }}$

Subscriptions: $\underline{\text { Click here }}$

Commercial reprints: $\underline{\text { Click here }}$

Terms of use : $\underline{\text { Click here }}$

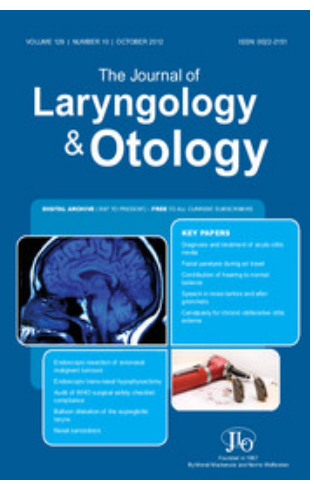

\title{
Adenomatoid hyperplasia of palatal minor salivary glands
}

C. Bryant, M. Manisali and A. W. Barrett

The Journal of Laryngology \& Otology / Volume 110 / Issue 02 / February 1996, pp 167 - 169

DOI: 10.1017/S0022215100133067, Published online: 29 June 2007

Link to this article: http://journals.cambridge.org/abstract S0022215100133067

How to cite this article:

C. Bryant, M. Manisali and A. W. Barrett (1996). Adenomatoid hyperplasia of palatal minor salivary glands. The Journal of Laryngology \& Otology, 110, pp 167-169 doi:10.1017/S0022215100133067

Request Permissions : $\underline{\text { Click here }}$ 


\title{
Adenomatoid hyperplasia of palatal minor salivary glands
}

\author{
C. Bryant, F.D.S., R.C.S.*, M. Manisali, M.B., B.S., M.Sc., F.F.D., R.C.S.I.*, A. W. Barrett, Ph.D., F.D.S. ${ }^{*}$, \\ R.C.S.†
}

\begin{abstract}
Adenomatoid hyperplasia of palatal minor mucous glands is rare but significant because the clinical appearance mimics malignant disease. The typical history of a painless, indolent palatal swelling, together with the histological picture of benign glandular hyperplasia and hypertrophy, are illustrated in this report.
\end{abstract}

Key words: Salivary gland diseases; Palate; Hyperplasia

\section{Introduction}

Adenomatoid hyperplasia of oral minor mucous salivary glands is an uncommon lesion which is most often encountered in the palate. Its importance lies in the clinical resemblance to more sinister disease. The principal histological features are hyperplasia and hypertrophy of mucous acini, changes which are of uncertain aetiology but which, like the clinical course, are entirely benign with adequate excision curative. Here we describe a case of adenomatoid hyperplasia which demonstrates the typical clinicopathological characteristics of the condition.

\section{Case report}

A 48-year-old Asian man was referred to the Department of Oral and Maxillofacial Surgery with a painless swelling in his palate which was first noted at a visit to a dental hygienist. The duration of the lesion was unknown, but the patient felt that the lump was slowly enlarging although there were no other symptoms. Review of his past medical history, physical examination, haematological

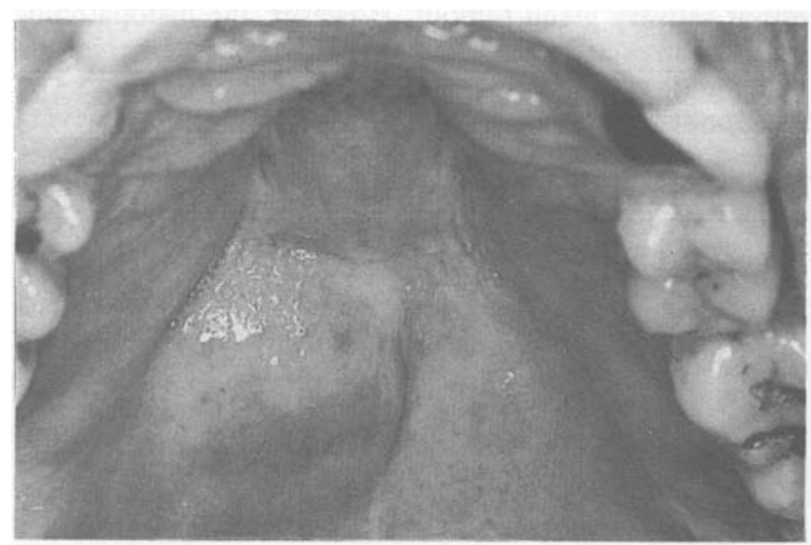

Fig. 1

Clinical photograph to show palatal swelling extending to the midline. and biochemical investigations were unremarkable. $\mathrm{He}$ was a non-smoker, and drank alcohol only occasionally.

Examination of the head and neck demonstrated no

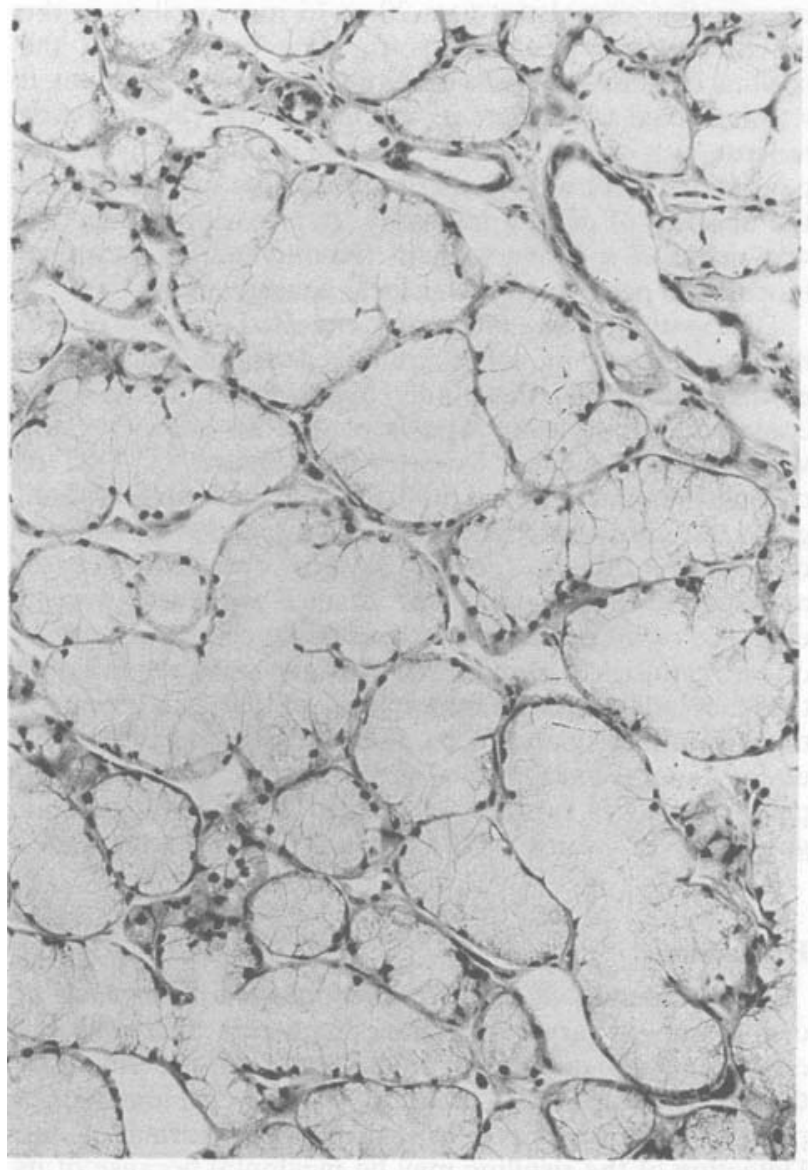

FIG. 2

Increased numbers of hypertrophic mucous acini showing nuclear displacement towards the basal pole. $(\mathrm{H} \& \mathrm{E} ; \times 40)$.

From the Departments of Maxillofacial Surgery* and Oral Pathology†, Eastman Dental Institute for Oral Health Care Sciences, London, UK.

Accepted for publication: 19 November 1995. 


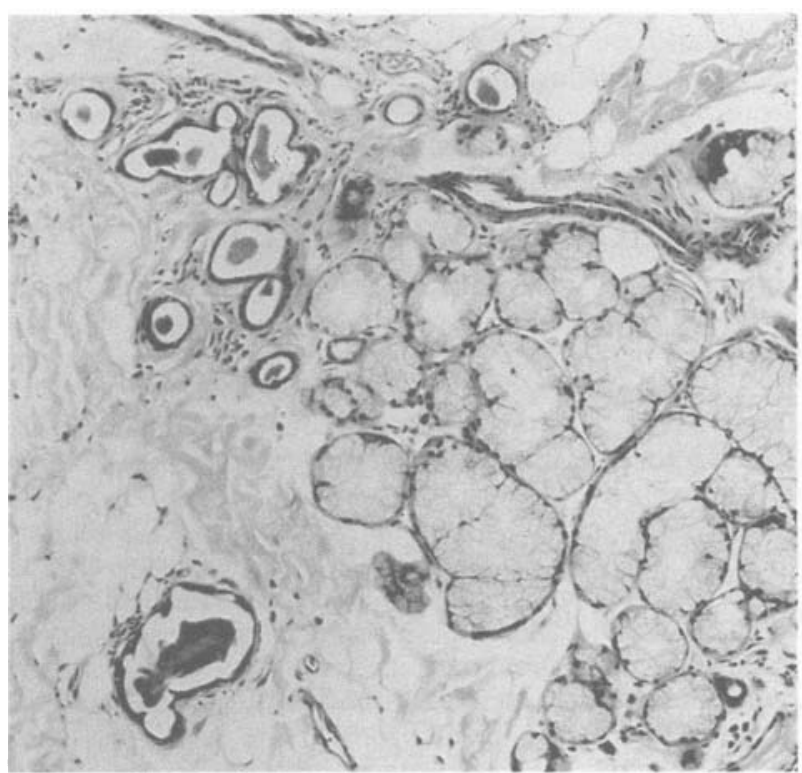

Fig. 3

The affected gland containing areas of glandular atrophy and fibrosis, with duct dilation and chronic inflammation. $(\mathrm{H} \& \mathrm{E} ; \times 25)$.

cervical lymphadenopathy or facial asymmetry. Intra-oral examination revealed a firm $20 \times 15 \mathrm{~mm}$ swelling at the junction of the hard and soft palate extending to the midline (Figure 1). This was neither tender nor fluctuant, it was not fixed to the underlying tissues and the overlying mucosa was intact and of normal colour. All of the permanent teeth were present and radiographs confirmed the absence of dental pathology. A provisional diagnosis was made of a salivary gland tumour and an incisional biopsy was performed under local anaesthetic.

Histopathological examination revealed a nodule of oral mucosa covered by orthokeratinized stratified squamous epithelium which was mildly hyperplastic. The corium contained hyperplastic lobules of mucous salivary gland which showed acinar hypertrophy (Figure 2). Foci of chronic inflammatory cell infiltration, mucus extravasation, gland fibrosis and atrophy were present, and some salivary ducts were dilated (Figure 3). However, the general architecture of the gland was retained and there was no evidence of invasion of the surrounding connective tissue, nor of cytological atypia. The features were regarded as those of adenomatoid hyperplasia of the palatal minor mucous salivary glands. Complete excision was performed under general anaesthesia, and the defect closed with a pack which was sutured into place. The patient made a good recovery, since when there has been no recurrence.

\section{Discussion}

Approximately 80 cases of adenomatoid hyperplasia of oral minor salivary glands have been reported since the condition was definitively identified and described by Giansanti et al. (1971). Patients typically present with a painless lump which is sessile, firm and of normal colour. Detection of the swelling may be incidental because of its indolent nature, and pain is usually due to repeated trauma with eventual ulceration (Barrett and Speight, 1995); one reported case where the mass was painful was situated close to carious teeth (DeLuke et al., 1992). As in the present case, the inviduals affected are usually middleaged, though a wide age range may be affected with a slight male preponderance (Arafat et al., 1981; Buchner et al., 1991; Barrett and Speight, 1995). The site affected in the present case is also as expected from previous studies; the hard and soft palate are by far the areas most often involved, but isolated cases have been reported in the mandibular retromolar, buccal, labial or ventral lingual mucosa (Brannon et al., 1985; Buchner et al., 1991: Barrett and Speight, 1995). It is apparent, therefore, that any oral site where mucous salivary glands are found may be affected.

The aetiology of adenomatoid hyperplasia, however, remains conjectural. Local trauma has been proposed as a likely cause because several instances have occurred in wearers of maxillary dentures which lie in close proximity to palatal lesions, or whch occlude against retromolar lesions (Devildos et al., 1976; Scully et al., 1992; Barrett and Speight, 1995). In one series, 14 out of 20 subjects either wore dentures or smoked tobacco and histological features were typically present that supported a traumatic origin, namely chronic inflammation of the affected glands, hyperplasia of the overlying mucosal epithelium, areas of mucus extravasation, glandular fibrosis and atrophy, ductal dilation (Figure 3) and hyperkeratosis of the orifice (Barrett and Speight, 1995). One series excluded those instances where mucus spillage and inflammation were prominent, but nevertheless noted inflammatory infiltrates in some of their remaining cases (Buchner et al., 1991). The individual described in this case neither smoked nor wore a denture, and the cause of the lesion is not apparent. The factors involved in sialadenosis of the major salivary glands do not produce adenomatoid hyperplasia (Seifert et al., 1986), which is restricted to minor glands. Whilst a hamartomatous element has been proposed (Arafat $e t$ al., 1981 ), this is unlikely in patients in their fourth to sixth decades.

The largest series reported to date indicates a predilection for Caucasians ( 90 per cent), with black and Hispanic populations less commonly affected (Buchner et al., 1991). Although the absence of Asian patients is highlighted in this series, a subsequent study (Barrett and Speight, 1995), and, of course, the present case, has shown Asian individuals may be affected on occasion. It might therefore be concluded that race is an insignificant feature, unless coincident environmental or social factors are instrumental in the aetiology of this lesion.

Adenomatoid hyperplasia has been described as 'a sheep in wolf's clothing' (Scully et al., 1992) and the lesion's significance lies in the clinical resemblance to a minor salivary gland tumour. However, the histopathological features are specific and do not resemble benign or malignant salivary neoplasms. The high incidence of malignant salivary gland tumours in the palate nevertheless means that biopsy of soft palatal swellings is mandatory, but once a diagnosis of adenomatoid hyperplasia is established, conservative excision is all that is required and and recurrence is exceptional.

\section{Acknowledgements}

The authors would like to thank Mr C. Hopper for allowing this case to be published and acknowledge the photographic assistance of Mr Paul Darkins.

\section{References}

Arafat, A., Brannon, R. B., Ellis, G. L. (1981) Adenomatoid hyperplasia of mucous salivary glands. Oral Surgery, Oral Medicine and Oral Pathology 52: 51-55.

Barrett, A. W., Speight, P. M. (1995) Adenomatoid hyperplasia of oral minor salivary glands. Oral Surgery, Oral Medicine and Oral Pathology 79: 482-487. 
Brannon, R. B., Houston, G. D., Meader, C. L. (1985) Adenomatoid hyperplasia of mucous salivary glands: A case involving the retromolar area. Oral Surgery, Oral Medicine and Oral Pathology 60: 188-190.

Buchner, A., Merrell, P. W., Carpenter, W. M., Leider, A. S. (1991) Adenomatoid hyperplasia of minor salivary glands. Oral Surgery, Oral Medicine and Oral Pathology 71: 583-587.

DeLuke, D. M., Sciubba, J. J., Livanos, G., Emmings, F. G. (1992) Painful mass in the palate. Journal of Oral and Maxillofacial Surgery 50: 59-61.

Devildos, L. R., Langlois, C. C. (1976) Minor salivary gland lesion presenting clinically as tumour. Oral Surgery, Oral Medicine and Oral Pathology 41: 657-659.

Giansanti, J. S., Baker, G. O., Waldron, C. A. (1971) Intraoral, mucinous, minor salivary gland lesions presenting clinically as tumors. Oral Surgery, Oral Medicine and Oral Pathology 32: $918-922$.
Scully, C., Eveson, J. W., Richards, A. (1992) Adenomatoid hyperplasia in the palate: another sheep in wolf's clothing. British Dental Journal 173: 141-142.

Seifert, G., Miehlke, A., Haubrich, J., Chilla, R. (1986) Diseases of the Salivary Glands. Georg Thieme Verlag, Stuttgart, p 80.

Address for correspondence:

Miss C. Bryant,

Department of Maxillofacial Surgery,

Eastman Dental Institute for Oral Health Care Sciences,

256 Grays Inn Road,

London WC1X 8LD.

Fax: 01719151259. 